\title{
Investigational Product Recall Plan
}

National Cancer Institute

\section{Source}

National Cancer Institute. Investigational Product Recall Plan. NCI Thesaurus. Code C115758.

A proposed method to document the recall process for an investigational product. 